\title{
The Development and Testing of a Child-inspired Advertising Disclosure to Alert Children to Digital and Embedded Advertising
}

Steffi De Jans, Ini Vanwesenbeeck, Veroline Cauberghe, Liselot Hudders, Esther Rozendaal \& Eva A. van Reijmersdal

To cite this article: Steffi De Jans, Ini Vanwesenbeeck, Veroline Cauberghe, Liselot Hudders, Esther Rozendaal \& Eva A. van Reijmersdal (2018): The Development and Testing of a Childinspired Advertising Disclosure to Alert Children to Digital and Embedded Advertising, Journal of Advertising, DOI: 10.1080/00913367.2018.1463580

To link to this article: https://doi.org/10.1080/00913367.2018.1463580

View supplementary material $₫$

Published online: 06 Jun 2018.

Submit your article to this journal $₫$

View related articles

View Crossmark data $\asymp$ 


\section{The Development and Testing of a Child-inspired Advertising Disclosure to Alert Children to Digital and Embedded Advertising}

Steffi De Jans

Ghent University, Ghent, Belgium

Ini Vanwesenbeeck

Ghent University, Ghent, Belgium

Veroline Cauberghe

Ghent University, Ghent, Belgium

Liselot Hudders

Ghent University, Ghent, Belgium

Esther Rozendaal

Radboud University, Nijmegen, the Netherlands

Eva A. van Reijmersdal

University of Amsterdam, Amsterdam, the Netherlands
Via three studies, this article aims to develop and test an advertising disclosure which is understandable for children (ages six to 12 years old) and which can alert them to different types of advertising in multiple media formats. First, cocreation workshops with 24 children (ages eight to 11 years old) were held to determine a

Address correspondence to Steffi De Jans, Ghent University, Department of Communication Sciences, Korte Meer 7-9-11, 9000 Ghent, Belgium. E-mail: Steffi.DeJans@UGent.be

Steffi De Jans (MS, Ghent University) is a doctoral student, Department of Communication Sciences, Ghent University, Ghent, Belgium.

Ini Vanwesenbeeck (PhD, University of Antwerp) is a postdoctoral researcher, Department of Communication Sciences, Ghent University, Ghent, Belgium.

Veroline Cauberghe ( $\mathrm{PhD}$, University of Antwerp) is an associate professor, Department of Communication Sciences, Ghent University, Ghent, Belgium.

Liselot Hudders (PhD, Ghent University) is an assistant professor, Department of Marketing and Department of Communication Sciences, Ghent University, Ghent, Belgium.

Esther Rozendaal ( $\mathrm{PhD}$, University of Amsterdam) is an assistant professor, Behavioural Science Institute, Radboud University, Nijmegen, the Netherlands.

Eva A. van Reijmersdal ( $\mathrm{PhD}$, University of Amsterdam) is an associate professor, Amsterdam School of Communication Research, University of Amsterdam, Amsterdam, the Netherlands. selection of disclosure designs based on insights from the target group. Second, two eye-tracking studies among 32 children (ages six to 12 years old) were conducted to test which of these disclosure designs attracted the most attention when the disclosures were integrated into a media context. These studies led to the selection of the final advertising disclosure: a black rectangular graphic with the word Reclame! (i.e., Dutch for "Advertising!") in yellow letters. Finally, a two-by-two, between-subjects experimental study (disclosure design: existing versus child-inspired advertising disclosure; advertising format: brand placement versus online banner advertising) with 157 children (ages 10 and 11 years old) was performed to test the effectiveness of the child-inspired disclosure by comparing it with existing ones. This study not only showed that children recognized, understood, and liked the child-inspired disclosure better than the existing ones, but they were also better able to recognize advertising after exposure to this child-inspired advertising disclosure.

Many legislative and self-regulatory principles (e.g., the Federal Trade Commission [FTC]'s Clear and Conspicuous Standard and the International Chamber of Commerce [ICC] Code's Article 9) formulate that commercial communications should be recognizable as such and that sponsors should be identified to the audience irrespective of the medium and format. These principles also define a special case for children. For example, 
Article 18 of the ICC Code prescribes that "marketing communications directed to children should be clearly distinguishable to them as such" (International Chamber of Commerce (ICC) 2017). The FTC further formulates recommendations to consider when developing an advertising disclosure. Specifically, marketers should consider the prominence of the disclosure, whether it is avoidable, and whether the language of the disclosure is understandable for the intended audience (Federal Trade Commission (FTC) 2013). However, it is not further specified how these disclosures should be designed, implemented, or monitored; therefore, the execution varies among countries, media channels, and advertising formats. Consequently, digital and embedded advertising is often not disclosed, or it is disclosed in different ways (e.g., "Adv" on Google; "Sponsored by" on YouTube; "Sponsored" on Facebook).

Recent studies on the effectiveness of advertising disclosures were mainly conducted among adults and suggest that advertising disclosures can increase advertising recognition (e.g., Boerman, van Reijmersdal, and Neijens 2014; Kim, Pasadeos, and Barban 2001). However, adults have difficulties recognizing and comprehending existing advertising disclosures (Boerman, van Reijmersdal, and Neijens 2012; Boerman, Willemsen, and Van Der Aa 2017; Campbell, Mohr, and Verlegh 2013; Tessitore and Geuens 2013), as these disclosures show deficiencies in terms of content, readability, and visibility (An and Kang 2013, 2014). Accordingly, Tessitore and Geuens (2013) advised public-policy makers to develop disclosures that stand out better (e.g., by using flashy colors), as the current disclosures pass under the radar of most viewers. Research concerning the effect of disclosures on activating children's advertising recognition is extremely limited and even less conclusive (e.g., An and Stern 2011; Panic, Cauberghe, and De Pelsmacker 2013). If even adults have difficulties recognizing and comprehending existing advertising disclosures, we expect that it is even more difficult for children to understand these different types of disclosures.

This study therefore aims to develop and test a childinspired advertising disclosure: a recognizable and understandable tool which successfully discloses advertising to children between the ages of six and 12 years old, and which is applicable to all advertising formats in different media platforms. Age 12 is an important age boundary in (self-)regulation, as most regulations and guidelines that restrict advertising to children are implemented for children aged 12 and younger (e.g., the EU Pledge). Age six was chosen as the lower limit of the age range because children under age six possess only limited advertising literacy (e.g., they can recognize TV advertising based only on perceptual features; Bandyopadhyay, Kindra, and Sharp 2001; Kunkel et al. 2004) and are usually not yet able to read (most children learn to read in first grade; Sénéchal and LeFevre 2002).

\section{THEORETICAL FRAMEWORK}

\section{The Need for Advertising Disclosures}

Advertising literacy refers to an individual's abilities and skills to cope with advertising (Boush, Friestad, and Rose 1994) and consists of two facets: dispositional and situational advertising literacy (Hudders et al. 2017). First, dispositional advertising literacy refers to an associative network of information nodes that can have a cognitive, moral, and/or affective meaning related to advertising. Situational advertising literacy refers to actually using and applying this knowledge when confronted with advertising.

Compared to adults, children are often seen as unable to defend themselves against advertising because they lack the cognitive skills to understand it (Rozendaal, Buijzen, and Valkenburg 2010). When children grow older, they acquire the cognitive and social competences that enable them to develop persuasion knowledge and, accordingly, advertising literacy (Gunter, Oates, and Blades 2004; John 1999). Between the ages of eight and 12, children are assumed to fully develop advertising literacy (Kunkel et al. 2004; Valkenburg and Cantor 2001). However, research comparing adults and children has found that, at age 12 , children do not necessarily possess an adultlike advertising literacy level (Rozendaal, Buijzen, and Valkenburg 2010).

Furthermore, digital and embedded advertising formats challenge children's abilities to recognize that they are being targeted by advertising. Embedded advertising formats often fully integrate the commercial content into the media content, are often very interactive and fun, and have a longer exposure time, meaning children are more involved with the commercial message (van Reijmersdal et al. 2010). This makes it challenging to identify the commercial content, even for adults. Children's cognitive and emotional capabilities have not yet been fully developed, making it even more difficult for them to recognize this advertising as such (An, Jin, and Park 2014; Wollslager 2009) and subsequently activate their advertising literacy. As a result, children are often not able to critically cope with embedded advertising.

Advertising recognition is considered especially crucial for children because this further activates children's associative networks concerning advertising, which subsequently helps them critically evaluate the advertisement (Hudders et al. 2017) and therefore prevents them from being subconsciously persuaded by advertising. To improve children's ability to recognize (embedded) advertising, they must be aided in doing so, for example, by 
implementing an advertising disclosure (John 1999). This is in line with the cued processors theory, which suggests that children are cued processors who are able to use and apply their advertising literacy only when they are encouraged to do so - that is, by implementing a cue (Brucks, Armstrong, and Goldberg 1988; Roedder 1981). Disclosures can create awareness of the commercial content and make it easier to discriminate between commercial content and entertainment (Tessitore and Geuens 2013).

\section{Characteristics of Advertising Disclosures}

Despite the assumption that a disclosure can assist children in recognizing advertising, its effectiveness depends on its details and characteristics (An and Stern 2011; Wojdynski and Evans 2016). Most of the studies that examined the effectiveness of the characteristics of advertising disclosures were conducted among adults (for an overview, see Online Appendix 1). Only a few studies have been conducted to test the different characteristics of advertising disclosures among children. With regard to exposure time, previous research has shown that a sixsecond disclosure is more effective in activating adolescents' (ages 13 to 17 years old) advertising literacy and subsequently decreasing advertising effects than a three-second disclosure (van Reijmersdal et al. 2017). With regard to timing, De Pauw, Hudders, and Cauberghe (2017) found that a disclosure displayed prior to (compared to during) the sponsored content was more effective in increasing advertising literacy among children (ages eight to 10 years old). In addition, Rozendaal, Buijs, and van Reijmersdal (2016) showed that a forewarning for manipulative intent (compared to a forewarning for commercial intent) increased children's (ages eight to 10 years old) skepticism toward the advertising and subsequently decreased their product desire.

Further, An and Stern's (2011) experimental study showed that interrupting an advergame (i.e., an ad break) did not increase children's (ages eight to 11 years old) understanding of advertising or their identification of the source. Finally, two studies on disclosure modality showed that a visual disclosure was more effective in increasing advertising literacy in the context of brand placement (among eight- to 10-year-olds; De Pauw, Hudders, and Cauberghe 2017); while an auditory disclosure was more effective in mitigating advertising effects of advergames (among eight- to 11-year-olds; An and Stern 2011). To our knowledge, no studies have been conducted to investigate how disclosures for children should actually look (i.e., visual look) or what semantic content they should have (i.e., wording; e.g., the text that appears within an advertising disclosure) to optimize advertising recognition among children. Therefore, this study investigates the optimal design (visual look and wording) for child-inspired advertising disclosures of digital and embedded advertising.

\section{Developing a Child-inspired Advertising Disclosure}

Given this literature review, we aim to develop an optimal, child-inspired advertising disclosure that can be incorporated into many different media platforms to disclose different advertising formats. The new disclosure should enable children to better recognize and comprehend it and to better associate it with all types of advertising. In addition, the child-inspired disclosure should help children discriminate between advertising and media content and thus enable them to recognize all advertising as such. The literature on warning label design suggests that symbols should have clear meanings for their intended audience; otherwise, they do not serve their purposes and their utility is low (Wogalter, Conzola, and SmithJackson 2002; Wogalter and Laughery 1996). Therefore, it is crucial to incorporate children's preferences and insights into the development of a meaningful symbol:

RQ1: Which disclosure characteristics (i.e., shape, color, wording, and usage of figures) are preferred by children to disclose advertising?

To answer research question 1, we first turned to the children themselves by organizing cocreation workshops. Sanders and Stappers (2008, p. 16) defined cocreation as "any act of collective creativity, i.e., creativity that is shared by two or more people." The main goal of the cocreation workshops was to identify which characteristics (i.e., shape, color, wording, and usage of figures) children prefer for an advertising disclosure. The results of this study were used to develop a limited number of disclosure designs.

In a follow-up study, we identified which combination of disclosure characteristics - thus, which disclosure design - led to the highest level of attention among children by using eye-tracking technology. This information is important because the disclosure's design might affect how much attention is being paid to it (Boerman, van Reijmersdal, and Neijens 2014). Therefore, the following research question was formulated: RQ2: Which disclosure design (i.e., combination of disclosure
characteristics) attracts children's attention to the
greatest extent?

In addition, we test the effectiveness of the childinspired disclosure design in terms of comprehensiveness and ability to help children recognize the commercial content. Previous studies, all using experimental designs, have 
shown that adults have difficulties recognizing and comprehending advertising disclosures. For example, Tessitore and Geuens (2013) tested the effect of the Belgian "PP" symbol (disclosing "product placement") and showed that only $16 \%$ of the participants recalled the advertising disclosure. Moreover, only $21 \%$ knew the correct meaning of the disclosure. In addition, in a study by Boerman, van Reijmersdal, and Neijens (2012), 52\% of the participants could not recall the advertising disclosure for brand placement. This was even lower in a study by Campbell, Mohr, and Verlegh (2013), in which only $25 \%$ recalled the advertising disclosure for brand placement. Further, more than two-thirds of the participants failed to recall the advertising disclosure when exposed to an advertorial (Kim, Pasadeos, and Barban 2001). In the context of native advertising, Wojdynski and Evans (2016) indicated that more than one-third of the participants did not look at the advertising disclosure. Very recently, Boerman, Willemsen, and Van Der Aa (2017) found that $56 \%$ did not recognize an advertising disclosure for sponsored posts on Facebook.

These results provide evidence for the assumption that even adults pay very little attention to the currently used advertising disclosures and have difficulty recognizing and comprehending them. Given that the child-inspired advertising disclosure design is based on cocreation workshops that focused on the preferences and comprehensibility among children and eye-tracking technology that detected which design attracted the most attention, we assumed that it would be more recognizable, understandable, and likeable for children than currently used advertising disclosures (in the country where the study was conducted).

\footnotetext{
H1: Children will have (a) better disclosure recognition, (b) better disclosure understanding, and (c) more disclosure preference after exposure to the child-inspired disclosure compared to the currently used advertising disclosures.
}

Furthermore, we test how disclosure design affects children's ability to recognize advertising. Due to the cocreation workshops with the target group, the childinspired disclosure should be more meaningful for children and should attract greater attention and, thus, be more effective. We expected that children would therefore have a better recognition of advertising after exposure to the child-inspired disclosure compared to currently used advertising disclosures, as the increased ability to recognize commercial content depends on the visual attention given to and the recognition of the advertising disclosures (Boerman, van Reijmersdal, and Neijens 2014).

H2: Children will recognize advertising better after exposure to the child-inspired advertising disclosure than after exposure to the currently used disclosures.

\section{EMPIRICAL RESEARCH}

To answer the research questions and test the proposed hypotheses, three studies were conducted. In the first study, four cocreation workshops were organized with children between the ages of eight and 11 (i.e., the analytical phase within consumer socialization theory; John 1999) to answer research question 1 . This specific age group was selected because we wanted the participants to possess a minimal level of advertising literacy. Around the age of eight, most children are capable of distinguishing television content from advertising, understanding advertising's intent, and recognizing advertising's source and intended audience (Rozendaal, Buijzen, and Valkenburg 2010, 2011). The purpose of this first study was to get insights from the target group to determine a first selection of disclosure designs.

A follow-up study tested which of these disclosure designs attracted the most attention from children (ages six to 12) to answer research question 2 and to determine the final advertising disclosure. This was done by conducting two eye-tracking studies among the children. We included the entire age group for which the advertising disclosure was being developed, as it is important that young children also notice and like the child-inspired advertising disclosure and that it also draws the attention of 12-year-olds. Eye-tracking technology allows the inclusion of young children, as no advertising literacy or elaborate language skills are required.

Finally, in the third study, the effectiveness of the child-inspired advertising disclosure was tested by implementing it into two advertising formats, namely brand placement and online banner advertising, to provide some information about the generalizability of the advertising disclosure's effectiveness. More specifically, we tested the child-inspired advertising disclosure by comparing it with advertising disclosures that are currently being used in Belgium (the country where the study was conducted) for brand placement and online banner advertising. These specific advertising formats were chosen because they are widely used to target children (e.g., often appear on websites targeting children) and are currently disclosed in Belgium by specific disclosures. This study was conducted among 10- and 11 -year-olds (the cued processors; one grade within the target group).

Institutional ethical approval for the studies was obtained from the ethical review board of the faculty where the research was conducted. Then the schools and teachers involved were asked for permission (in Study 1 and Study 3), and parental consent was asked for all children before they could participate in the study. The participants were offered an incentive for participation. 


\section{Study 1: Cocreation Workshops with Children Method}

Participants Four cocreation workshops with children (ages 8 through 11) were organized. In total, 24 children $\left(M_{\mathrm{age}}=9.96, \mathrm{SD}=.96\right)$ participated, of which $50 \%$ were boys. In each cocreation workshop, six children participated (both boys and girls). The cocreation workshops were held in December 2016 at one elementary school in a West European country.

Procedure of Cocreation Workshops Each cocreation workshop lasted about 50 minutes. Three researchers were always present to guide the cocreation workshops: one acted as moderator, one as assistant, and one as observer. First, a short introduction (approximately 10 minutes) was given in which the children were taught about advertising (literacy; e.g., what advertising is and where advertising is displayed). The children were also taught about the digital and embedded advertising formats (e.g., advergames and brand placement) that they encounter daily. This introduction was developed based on the advertising literacy training session used in the study of Hudders, Cauberghe, and Panic (2016). Then, the function of disclosures ("symbols") was explained by giving examples of disclosures that are used in Belgium (the country where the data collection occurred), such as traffic and safety signs, the "PP" symbol, and the "Advertenties" symbol (Dutch for "Advertisements") placed on websites to disclose online banners.

With regard to advertising disclosures, the emphasis was mainly on advertising recognition, as this is the main goal of advertising disclosures. Finally, the children were informed that the researchers planned to develop a new symbol to disclose advertising and that the researchers needed their help to do it. A PowerPoint presentation was developed by the researchers to guide the introduction (see Online Appendix 2). After the introduction, a group conversation of about 10 minutes was held. Children were asked how they define advertising and which words they use to identify advertising. They were also asked which figures or symbols they associate with advertising. The children could write down or draw their ideas on sticky notes. The sticky notes were then collected, placed on a whiteboard, and used as a starting point for the group conversation. Afterward, the children were asked to individually craft their own symbols to disclose advertising on an A5-size paper. After 15 minutes, the children were asked to finalize their symbols, and then they were asked to explain to the group why they used specific colors, shapes, words, and so on. The researchers also proposed specific colors, shapes, words, and figures (see Online Appendices 3, 4, 5, and 6) that were based on previous research on cues and symbols (e.g., the color red was proposed because it is perceived as most hazardous in the warning label literature; Wogalter et al. 1995) and asked the children their opinions about these aspects with regard to a disclosure to alert them to advertising. This last group conversation lasted about 15 minutes. During the various group conversations, the children were encouraged to interact with one another.

Data Analysis NVivo, a qualitative data analysis software package, was used to analyze the data. We used an a priori approach to code the data (Mortelmans 2007). Specifically, we started from a codebook and attached specific codes to the information from the cocreation workshops (for the codebook, see Table 1). Both the data from the group discussions and the data gathered from the constructed disclosures (see Figure 1) and sticky notes was coded. The codebook referred to different visual aspects of an advertising disclosure, namely, color, shape, wording, figure, and punctuation mark.

\section{Results}

With regard to shape, the respondents agreed that the shape of an advertising disclosure should stand out. For example, one respondent referred to the fact that a disclosure is shown for only a few seconds and therefore should be immediately noticeable. According to the participants, the use of rounded corners could help to grab children's attention, as these are not often used in the context of advertising. The triangle was most preferred because it represents danger, and an explosion shape was also mentioned several times. There was, however, no univocal opinion about the use of a circle for a disclosure. Some respondents believed it was too common and would not stand out; other respondents thought it was a good shape for a disclosure. A rectangle and an oval shape were also mentioned as possible alternatives. The children advised us not to use a square-shaped advertising disclosure.

Further, the respondents acknowledged that an advertising disclosure should be displayed in a striking color, most preferably red or yellow. The children did not prefer black as a standalone color to develop a disclosure but said that they would use this color in combination with red and/or yellow, since this color combination creates a contrasting effect.

In addition, the wording of the disclosure was very clear for the children, as there was a consensus on the word reclame (i.e., the most commonly used word in Dutch for "advertising"). Another possible alternative concerning the preferred wording of a disclosure was dit is reclame (i.e., "This is advertising"). The opinions about bevat reclame (i.e., "contains advertising") were 
TABLE 1

Codebook.

\begin{tabular}{|c|c|c|c|}
\hline Codes & Subcodes & $\begin{array}{l}\text { Number of } \\
\text { References }\end{array}$ & Quotes \\
\hline \multirow[t]{2}{*}{ Shape } & Include & 27 & $\begin{array}{l}\text { Respondent (session 2, age 11, girl): "I think it should be } \\
\text { in a striking form, with a striking color. So people will } \\
\text { notice it when it's only visible on screen for } \\
\text { five seconds." }\end{array}$ \\
\hline & Exclude & 13 & $\begin{array}{l}\text { Respondent (session 2, age 11, girl): "With a square, I } \\
\text { don't think of advertising. That's the shape I see the } \\
\text { least in advertising." }\end{array}$ \\
\hline \multirow[t]{2}{*}{ Wording } & Include & 28 & $\begin{array}{l}\text { Respondent (session 2, age 10, girl): "If it is a regular } \\
\text { advertisement, I would choose 'Advertising.' Or 'This is } \\
\text { advertising.' But if it is really during a program, I would } \\
\text { choose 'Contains advertising."” }\end{array}$ \\
\hline & Exclude & 15 & $\begin{array}{l}\text { Respondent (session 2, age 10, girl): "I would not use an } \\
\text { abbreviation. Because it is . . I would not immediately } \\
\text { recognize it. I would not know what it stands for." }\end{array}$ \\
\hline \multirow[t]{2}{*}{ Color } & Include & 19 & $\begin{array}{l}\text { Respondent (session } 4 \text {, age } 10 \text {, boy): "I think yellow and } \\
\text { red are good colors . . . because they are both strik- } \\
\text { ing colors." }\end{array}$ \\
\hline & Exclude & 5 & $\begin{array}{l}\text { Respondent (session 4, age 11, boy): "I would definitely } \\
\text { not use green." Respondent (session } 4 \text {, age } 10 \text {, boy): } \\
\text { "Yes, me neither. It doesn't fit with advertising. It also } \\
\text { not a striking color." }\end{array}$ \\
\hline \multirow[t]{2}{*}{ Figure } & Include & 20 & $\begin{array}{l}\text { Respondent (session } 1 \text {, age } 9 \text {, boy, talking about the mega- } \\
\text { phone): "It looks like the guy calls it out . . . } \\
\text { advertising!" }\end{array}$ \\
\hline & Exclude & 12 & $\begin{array}{l}\text { Respondent (session 1, age 9, boy): "The guy with the } \\
\text { coin, it doesn't fit with advertising." }\end{array}$ \\
\hline \multirow[t]{2}{*}{ Punctuation mark } & Include & 10 & $\begin{array}{l}\text { Respondent (session 2, age 11, girl): "It depends. When it } \\
\text { is just the word 'advertising,' then I would definitely use } \\
\text { an exclamation point. When it is a sentence, then I think } \\
\text { it is not necessary to use a punctuation mark." }\end{array}$ \\
\hline & Exclude & 0 & 1 \\
\hline
\end{tabular}

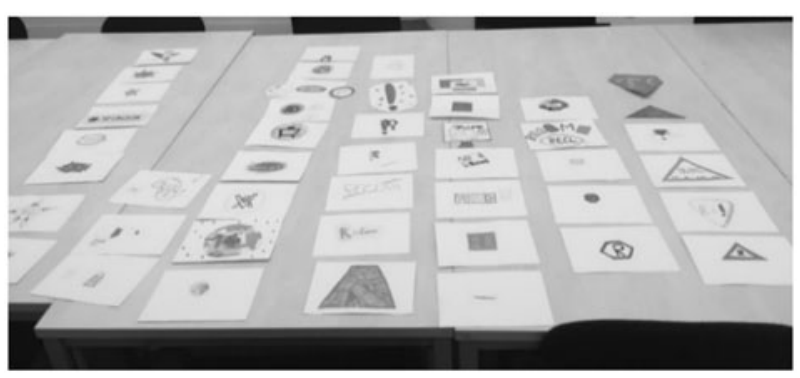

FIGURE 1. Constructed disclosures of the children.

inconsistent. Words derived from the English vocabulary, like advertentie (i.e., Dutch for "advertisement"), were less preferred, suggesting that an advertising disclosure should use a local adaptation of language instead of derived terms from other languages. Further, most children, especially the youngest ones, did not know or understand terms such as commerciële info (i.e., "commercial information"), gesponsord (i.e., "sponsored"), or product placement, words that are currently used to disclose advertising. There was also a consensus that the use of an abbreviation is a bad idea, because most children would not understand what the abbreviation stands for. When the children were asked about punctuation marks, they all preferred an exclamation mark, especially in combination with the word reclame.

Last, the researchers proposed specific figures that fit into the context of advertising (e.g., a shopping cart, a megaphone, a coin). Most children preferred the megaphone; moreover, the respondents suggested that the 
1.
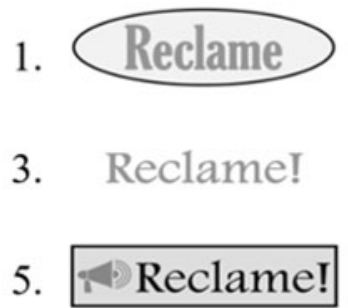

3. Reclame!
2. Reclame?

4. Reclame!

6. $\triangle$ Reclame
FIGURE 2. Six developed disclosure designs after Study 1.

word reclame should come out of the megaphone. There was no consensus on the coin; the children did not directly associate advertising with money.

\section{Conclusion-Study 1}

Based on the results of the cocreation workshops, six different disclosure designs were developed (see Figure 2). Due to practical considerations concerning the size of the disclosure and to avoid any negative connotations (e.g., "advertising is dangerous or bad"), no disclosures were developed with an explosion or triangle shape. In two follow-up studies (Studies 2a and 2b), we tested which of the six disclosure designs attracted the most attention from children by conducting eye-tracking studies.

\section{Study 2a: Eye-tracking Study 1 Method}

Participants, Stimuli, and Procedure In this study, 18 children (ages six to 10) participated $(M=8.11$, $\mathrm{SD}=1.41$ ), and $66.7 \%$ of them were boys. The children were recruited using the snowball method. The study was conducted in February 2017.

The six disclosure designs were incorporated into screenshots of the children's website Nickelodeon. Each screenshot of a web page contained two different online banners: one on top of the web page and one in the right sidebar. These online banners were different for each of the 18 screenshots. On top of each online banner, an advertising disclosure was placed in the upper-right corner. Thus, each screenshot of Nickelodeon contained two different online banners and, accordingly, two identical advertising disclosures (see Online Appendix 7 for an example of a created screenshot). Because we constructed six different advertising disclosures, six screenshots were manipulated. The screenshots of Nickelodeon containing the online banners and advertising disclosures were interspersed with screenshots of websites of other children's channels that did not contain any online banners or advertising disclosures. In total, using a within-subjects experimental design, the children were exposed to all 18 screenshots of the websites for children's channels. The screenshots of the websites were randomized to avoid order effects.

The children first had to answer a few sociodemographic questions, such as gender and age. Then they were told to look at the different screenshots. One researcher was always present to make sure the participants looked at all the screenshots and could ask questions if necessary. The eye-tracking study lasted approximately 10 minutes per participant.

Apparatus and Measures The eye-tracking study was conducted using the SMI Mobile Eye Tracking Device IViewX RED. This device allowed for recording at a frequency of $250 \mathrm{~Hz}$. Experiment Center software (3.7; SMI Experiment Suite $360^{\circ}$ ) was used for stimuli presentation and data collection. A five-point calibration was performed before each recording session. The obtained data were analyzed using SMI Behavioral and Gaze Analysis software (SMI BeGaze) and were subsequently transferred to SPSS 24 to conduct additional analyses.

Five different attentional indices were extracted for the present study: (1) number of fixations on areas of interest (AOIs) disclosure on top of the website; (2) number of fixations on AOI disclosure on the right sidebar; (3) total number of fixations; (4) entry time: average duration for the first fixation on the AOIs; (5) dwell time: (ms) sum of durations from all fixations and saccades that hit the AOIs; $(\%)$ dwell time (ms)/(end time - start time).

\section{Results}

Before analyzing the data, specific AOIs were identified $(126 \times 36$ pixels per AOI). In particular, the advertising disclosures were identified as AOIs. We identified two AOIs per screenshot; 12 AOIs were identified in total.

The eye-tracking data revealed that there were no fixations on advertising disclosures 1, 2, 4, 5, and 6 (see Online Appendices 8, 9, 10, 11, and 12 for the scan paths). The data did show two fixations on disclosure 3 (the advertising disclosure without background containing the word Reclame! in red; see Online Appendix 13 for the scan path). Table 2 summarizes the data obtained from the eye-tracking study.

A repeated-measures analysis of variance (ANOVA) was conducted to examine whether the participants fixated significantly more on advertising disclosure 3 than on the other advertising disclosures. Age was incorporated as a covariate in the analysis to ensure that differences between the different factors could not be attributed to age differences. The analysis revealed that the 
TABLE 2

Summary of Results Eye-Tracking Study 1.

\begin{tabular}{|c|c|c|c|c|c|}
\hline Cue & $\begin{array}{c}\text { Number of Fixations } \\
\text { (Cue on Top of } \\
\text { the Website) }\end{array}$ & $\begin{array}{l}\text { Number of Fixations } \\
\text { (Cue in Right Sidebar) }\end{array}$ & $\begin{array}{l}\text { Total Number } \\
\text { of Fixations }\end{array}$ & $\begin{array}{c}\text { Entry Time } \\
\text { (Cue on Top; Cue } \\
\text { Right Sidebar) }\end{array}$ & $\begin{array}{c}\text { Dwell Time } \\
\text { (Cue on Top; } \\
\text { Cue Right Sidebar) }\end{array}$ \\
\hline Reclame! & $0(0 \%)$ & $0(0 \%)$ & 0 & 1 & I \\
\hline Reclame? & $0(0 \%)$ & $0(0 \%)$ & 0 & / & / \\
\hline Reclame! & $1(5.6 \%)$ & $1(5.6 \%)$ & 2 & $\begin{array}{l}7479.3 \mathrm{~ms} \\
7882.9 \mathrm{~ms}\end{array}$ & $\begin{array}{l}60.3 \mathrm{~ms}(0.6 \%) \\
14.8 \mathrm{~ms}(0.1 \%)\end{array}$ \\
\hline Reclame! & $0(0 \%)$ & $0(0 \%)$ & 0 & I & i \\
\hline$\triangle$ Reclame & $0(0 \%)$ & $0(0 \%)$ & 0 & I & 1 \\
\hline Reclame & $0(0 \%)$ & $0(0 \%)$ & 0 & 1 & 1 \\
\hline
\end{tabular}

repeated-measures ANOVA was not significant ( $F$ $(1)=.12, p=.732)$. Thus, the children did not fixate significantly more on advertising disclosure $3(M=.11$, $\mathrm{SD}=.08)$ compared to advertising disclosures $1(M=.00$, $\mathrm{SD}=.00), 2(M=.00, \mathrm{SD}=.00), 4(M=.00, \mathrm{SD}=.00), 5$ $(M=.00, \mathrm{SD}=.00)$, and $6(M=.00, \mathrm{SD}=.00)$.

\section{Conclusion-Study $2 a$}

To conclude, we did not find a significant difference in the total number of fixations among the six different disclosure designs. In total, there were only two fixations on disclosure 3 (the word reclame in red with an exclamation mark, without a background) and no fixations on the other five advertising disclosures. Therefore, we could not determine which of the advertising disclosures attracted the most attention from the children based on these results. When looking at the scan paths of the different screenshots of Nickelodeon containing the online banners and advertising disclosures, we noticed that many of the children did fixate on the online banners; however, they did not look at the advertising disclosures in the upper-right corner of the online banners. Mostly, the children fixated on the banner centrally. Thus, although the disclosures did not attract children's attention, there appeared to be no banner blindness among these children. Therefore, we decided to conduct an additional eye-tracking study in which we opted to place the advertising disclosures on top of the online banners in the center (instead of in the upper-right corner) to ensure that the disclosures would attract greater attention.

\section{Study 2b: Eye-tracking Study 2 Method}

Participants, Stimuli, and Procedure Twenty-four children (ages 7 through 12) participated in the study $(M=8.67, \mathrm{SD}=1.55)$, of which 17 were boys $(70.8 \%)$. The study was conducted in February 2017. The stimulus material and design used in this study were similar to those in Study 2a; however, in this study, the disclosures were placed on top of the online banners in the center (instead of in the upper-right corner). Two existing online banners (one for Volkswagen and one for Land Rover) were selected to display on the screenshot of the Nickelodeon website. These banners were actually displayed together on the Nickelodeon website at the moment the screenshot was taken. These two banners were displayed on each of the screenshots of Nickelodeon to control for the possibility that differences in children's attention to the disclosures could be attributed to differences in their preferences for the online banners. Using a within-subjects experimental design, the children were again exposed to the 18 screenshots (see Online Appendix 14 for an example of a created screenshot). The procedure was the same as the procedure in Study 2a.

Apparatus and Measures The eye-tracking study was conducted using the same eye-tracking device as in Study 2a, and the same attentional indices as in Study 2a were extracted for this study.

\section{Results}

In accordance with Study 2a, the advertising disclosures were again identified as AOIs. The eye-tracking 
TABLE 3

Summary of Results Eye-Tracking Study 2.

\begin{tabular}{|c|c|c|c|c|c|}
\hline Cue & $\begin{array}{l}\text { Number of Fixations } \\
\text { (Cue on Top of } \\
\text { the Website) }\end{array}$ & $\begin{array}{l}\text { Number of Fixations } \\
\text { (Cue in Right Sidebar) }\end{array}$ & $\begin{array}{l}\text { Total Number } \\
\text { of Fixations }\end{array}$ & $\begin{array}{c}\text { Entry Time } \\
\text { (Cue on Top; Cue } \\
\text { Right Sidebar) }\end{array}$ & $\begin{array}{c}\text { Dwell Time } \\
\text { (Cue on Top; Cue } \\
\text { Right Sidebar) }\end{array}$ \\
\hline Reclame! & $1(4.2 \%)$ & $1(4.2 \%)$ & 2 & $\begin{array}{c}11011.2 \mathrm{~ms} \\
4000.1 \mathrm{~ms}\end{array}$ & $\begin{array}{l}15.3 \mathrm{~ms}(0.1 \%) \\
34.8 \mathrm{~ms}(0.3 \%)\end{array}$ \\
\hline Reclame? & $0(0 \%)$ & $2(8.3 \%)$ & 2 & $\begin{array}{c}/ \\
5898.3 \mathrm{~ms}\end{array}$ & $50.1 \mathrm{~ms}(0.4 \%)$ \\
\hline Reclame! & $1(4.2 \%)$ & $1(4.2 \%)$ & 2 & $\begin{array}{l}10080.0 \mathrm{~ms} \\
2425.6 \mathrm{~ms}\end{array}$ & $\begin{array}{l}20.2 \mathrm{~ms}(0.2 \%) \\
48.7 \mathrm{~ms}(0.4 \%)\end{array}$ \\
\hline Reclame! & $2(8.3 \%)$ & $4(16.7 \%)$ & 6 & $\begin{array}{c}10990.1 \mathrm{~ms} \\
996.1 \mathrm{~ms}\end{array}$ & $\begin{array}{c}68.9 \mathrm{~ms}(0.5 \%) \\
130.1 \mathrm{~ms}(1.0 \%)\end{array}$ \\
\hline$\triangle$ Reclame & $0(0 \%)$ & $0(0 \%)$ & 0 & / & 1 \\
\hline Reclame & $2(8.3 \%)$ & $1(4.2 \%)$ & 3 & $\begin{array}{c}8821.0 \mathrm{~ms} \\
12575.9 \mathrm{~ms}\end{array}$ & $\begin{array}{c}28.5 \mathrm{~ms}(0.2 \%) \\
7.0 \mathrm{~ms}(0.1 \%)\end{array}$ \\
\hline
\end{tabular}

data revealed that the total number of fixations was highest for advertising disclosure 4 (the black rectangular disclosure with Reclame! in yellow letters). More specifically, in total, there were six fixations on disclosure 4 , whereas the total number of fixations on disclosures $1,2,3,5$, and 6 were, respectively, two, two, two, zero, and three (see Online Appendices 15, 16, 17, 18, 19, and 20 for the scan paths). A summary of the data obtained from the second eye-tracking study is presented in Table 3 .

We further analyzed these data using SPSS 24 and conducted a repeated-measures ANOVA to compare the total number of fixations among the six advertising disclosures. Age was again incorporated as a covariate. The repeatedmeasures ANOVA showed to be significant $(F(2)=3.05$, $p=.047)$. In particular, a least significance difference (LSD) post hoc test revealed that the children paid significantly more attention to disclosure $4(M=.25, \mathrm{SD}=.11)$ than to disclosure $5(M=.00, \mathrm{SD}=.00)$. There were, however, no significant differences between disclosure 4 and the other disclosures: disclosure $1 \quad(M=.08$, $\mathrm{SD}=.09), 2(M=.08, \mathrm{SD}=.06), 3(M=.08, \mathrm{SD}=.06)$, and $6(M=.13, \mathrm{SD}=.07)$.

\section{Conclusion-Study $2 b$}

We can conclude, in general, that the children still paid very little attention to the different disclosure designs, as the eye tracker recorded only a few fixations on the advertising disclosures. We did find six fixations on advertising disclosure 4 , which seemed to be significantly more than the fixations recorded for disclosure 5. Based on these results, disclosure 4 (a black rectangular disclosure with Reclame! in yellow letters) was selected as the

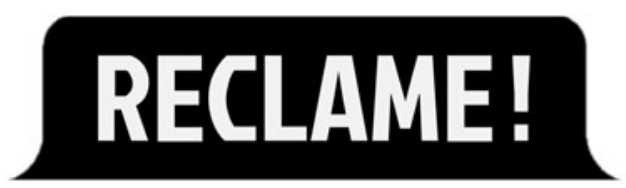

FIGURE 3. The child-inspired advertising disclosure.

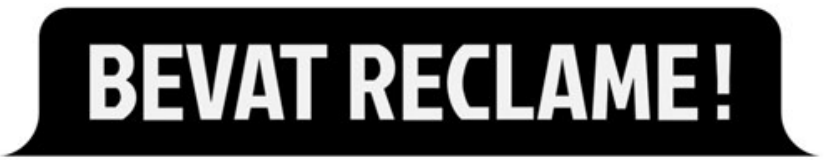

FIGURE 4. The additional developed advertising disclosure to disclose brand integration.

child-inspired advertising disclosure to alert children to advertising. The selected advertising disclosure was further refined by a graphic designer to make it look more professional (see Figure 3). For example, the childinspired advertising disclosure was given rounded corners (as proposed by the children in the cocreation workshops) and a light pulse animation. Also, an additional disclosure was created with the same design but containing the phrase bevat reclame ("contains advertising" in Dutch) to disclose different types of brand integration in media content (see Figure 4).

\section{Study 3: Experimental Study Testing Ad Disclosure Effectiveness Method}

Design and Procedure A two-by-two between-subjects experimental study (disclosure design: existing versus 
child-inspired advertising disclosure; advertising format: brand placement versus online banner advertising) was conducted to examine the effectiveness of the childinspired disclosure and compare it with those currently used in Belgium for online banners (Advertenties logo) and brand placement (PP logo). The placement of the disclosures was manipulated by showing either the existing or child-inspired advertising disclosure. In the brand placement condition, the children first watched a short TV program excerpt, after which they had to fill out a questionnaire. In the online banner condition, the children were first asked to surf on a website and then to fill out the same questionnaire.

Participants In this study, 157 children (ages 10 and $11 ; M=10.27, \mathrm{SD}=.45$ ) participated, 91 of whom were girls $(58 \%)$. The children were randomly recruited from seven different elementary schools in a West European country.

Stimulus Material For the manipulation of the brand placement, a short excerpt (of exactly two minutes) of The Voice Kids, a well-known reality TV program in Belgium, was selected. This excerpt of the TV program contained a prominent placement of the brand Choco!Choco!, a brand of chocolate milk. The product was shown several times and appeared for exactly 42 seconds on screen (see Online Appendix 21 for a screenshot of the excerpt). We chose the brand Choco!Choco! because it is equally liked by both boys and girls ("How much do you like the brand Choco!Choco!?" was answered on a 5-point Likert-scale from Not at all to Very much; $M=3.06, \mathrm{SD}=1.01$; $t(155)=-.12, p=.901)$. In addition, the children in the sample were moderately familiar with the brand Choco!Choco! ("Had you already heard of the brand Choco!Choco! before this study?" was answered on a 5-point Likert-type scale from Definitely not to Definitely; $M=2.96, \mathrm{SD}=1.69$ ). Both brand liking and brand familiarity were measured with one item because constructs in marketing that consist of a concrete singular object and a concrete attribute should be measured with single-item measures (Bergkvist and Rossiter 2007). The excerpt was projected on a big screen in front of the classroom.

In the brand placement condition, disclosure design was manipulated as follows. In the existing advertising disclosure condition, the Belgian PP symbol (for "product placement"; see Online Appendix 22) appeared on screen for exactly six seconds at the beginning of the excerpt and exactly six seconds at the end of the excerpt. The childinspired disclosure (bevat reclame, i.e., "contains advertising" in Dutch) appeared on screen for six seconds at the beginning and at the end of the excerpt in the child-inspired advertising disclosure condition. The exposure time of six seconds was carefully chosen based on the studies of Boerman, van Reijmersdal, and Neijens (2012) and van Reijmersdal et al. (2017), which showed that a six-second disclosure is more effective than a three-second disclosure in activating advertising literacy and further attenuating advertising effects. The modality of the advertising disclosures was also held constant by exposing the participants only to visual advertising disclosures, because De Pauw, Hudders, and Cauberghe (2017) showed in their study that a visual advertising disclosure is more effective in activating children's advertising literacy for brand placement than an auditory disclosure.

The online banner advertising was manipulated by placing an online banner on a self-constructed and controlled website for children. We constructed a mock website for the TV program The Voice Kids to keep the website as controlled as possible (both for content and advertising). The mock website allowed us to control the advertising message and include the advertising disclosure in a realistic way. The design and content of the website were based on the actual The Voice Kids website that was online at the time the program aired on television. The website contained images, articles, a TV guide, and so on. On the website, an online banner for the brand Choco!Choco! was placed on top of each web page in the center (see Online Appendix 23 for a screenshot of the mock website). The children surfed the website for exactly two minutes. Hence, in all the conditions, the children were exposed to the medium for the same amount of time.

To manipulate disclosure design in the online banner advertising condition, the first group of children surfed the website containing the online banner for Choco!Choco! On top of this online banner was placed the existing Belgian advertising disclosure for online banners (a black rectangular graphic containing the word Advertisements in white; see Online Appendix 24). A second group of children surfed the same website with the same online banner and the child-inspired disclosure on top of the banner. In both conditions, the advertising disclosures were placed on top of the online banners in the center, based on the results obtained from the two eye-tracking studies, which showed that children paid relatively more attention to the advertising disclosures when they were placed in the center instead of the upperright corner of the online banners. In contrast to the brand placement condition, the advertising disclosures were constantly displayed on the online banners when the children were surfing the websites, as this is also the case in real life. The modality of the advertising disclosures was again held constant by implementing only visual advertising disclosures, similar to the brand placement condition. 
Measures The questionnaire contained smileys and icons because it was adapted to the cognitive abilities of the children (Mallinckrodt and Mizerski 2007; see Online Appendix 25 for a table with the measures). First, the children's recognition of advertising was measured by one item: "Did you see advertising in this TV excerpt/on this website?" This question was answered on a 5-point Likert-type scale ranging from Definitely not to Definitely (Waiguny, Nelson, and Terlutter 2014). Next, several disclosure variables were gauged. Disclosure recognition was measured by one item following Tessitore and Geuens (2013): "Which of these symbols did you see during the TV excerpt/on the website (if you saw one)?" Participants could choose from five possible symbols or the answer $I$ did not see a symbol during the TV excerpt/on the website. The children could only indicate one answer.

Because the children might not be aware that the TV clip or website contained an advertising disclosure, we included the phrase "In the TV excerpt/on the website, you could see this symbol," which was accompanied by a picture of the concerned advertising disclosure. We then measured disclosure understanding with one item: "Do you know what this symbol means?" (Tessitore and Geuens 2013). This question was an open-ended question and was recoded as Correct or Incorrect. Finally, disclosure preference was measured by one item: "How much do you like this symbol?" This item was measured on a 5point Likert-type scale ranging from Not at all to Very much.

\section{Results}

Disclosure Recognition A chi-square test was conducted to examine the main effect of disclosure design on disclosure recognition. The analysis was significant $\left(\chi^{2}\right.$ $(1)=13.00, p<.001, \varphi=.29)$ and showed that disclosure recognition was higher for the child-inspired disclosure (49.4\% correct recognition) than for the existing ones (21.8\% correct recognition; $z=3.6, p<.001)$. This result confirmed hypothesis $1 \mathrm{a}$.

Specifically, for the brand placement condition, the chi-square test was significant $\left(\chi^{2}(1)=14.65, p<.001\right.$, $\varphi=.43$ ). Disclosure recognition was significantly higher for the child-inspired disclosure $(64.9 \%$ correct recognition) compared to the existing one $(22.7 \%$ correct recognition; $z=3.8, p<.001)$. For the online banner condition, the main effect of disclosure design was not significant $\left(\chi^{2}\right.$ $(1)=2.09, p=.148, \varphi=.17)$. Respectively, $20.6 \%$ and $35.7 \%$ of the children could correctly recognize the existing and the child-inspired advertising disclosures. Although more children could correctly recognize the child-inspired than the existing advertising disclosure, this difference was not significant $(z=1.4, p=.149)$.
Disclosure Understanding A chi-square test revealed a significant main effect of disclosure design on disclosure understanding $\left(\chi^{2}(1)=55.09, p<.001, \varphi=.59\right)$. The children comprehended the child-inspired disclosure better (79.7\% correct understanding) than the existing disclosure designs $(20.5 \%$ correct understanding; $z=7.4, p<.001)$, which confirmed hypothesis $1 \mathrm{~b}$.

In addition, two separate chi-square tests were conducted (one for each advertising format) that showed significant main effects for both brand placement $\left(\chi^{2}\right.$ $(1)=47.12, p<.001, \varphi=.76)$ and online banner advertising $\left(\chi^{2}(1)=12.84, p<.001, \varphi=.41\right)$. In the brand placement condition, only $2.3 \%$ of the children knew the correct meaning of the Belgian PP symbol, whereas $75.7 \%$ understood the correct meaning of the childinspired disclosure $(z=6.9, p<.001)$. In addition, $44.1 \%$ of the children understood the meaning of the label that currently discloses online banners, while $83.3 \%$ knew the correct meaning of the child-inspired advertising disclosure $(z=3.6, p<.001)$.

Disclosure Preference To examine the main effect of disclosure design on disclosure preference and the interaction effect with advertising format, we conducted a univariate ANOVA. This analysis showed a significant main effect of disclosure design on disclosure preference $(F(1$, $\left.153)=4.68, p=.024, \eta_{p}{ }^{2}=.03\right)$. More specifically, the analysis showed that children liked the child-inspired disclosure $(M=2.92, \mathrm{SD}=1.02)$ more than the existing ones $(M=2.56, \mathrm{SD}=.88)$. This result confirmed hypothesis $1 \mathrm{c}$.

The interaction effect of disclosure design and advertising format on disclosure preference was not significant $(F$ $\left.(1,153)=.72, p=.375, \eta_{p}{ }^{2}=.01\right)$, indicating no differences between the online banner and brand placement conditions.

Recognition of Advertising Finally, a univariate ANOVA showed that the main effect of disclosure design on the recognition of advertising was significant $(F$ (1, $\left.153)=4.54, p=.035, \eta_{p}{ }^{2}=.03\right)$. In particular, the analysis showed that the children recognized the advertising better when exposed to the child-inspired disclosure $(M=3.72$, $\mathrm{SD}=1.15)$ than when exposed to the existing ones $(M=3.29, \mathrm{SD}=1.29)$, which confirmed hypothesis 2 . However, it is important to note that the children recognized the advertising fairly well even after exposure to the existing disclosures, indicating that both types of disclosures assist children in recognizing advertising.

The interaction effect of disclosure design and advertising format on advertising recognition was not significant $\left(F(1,153)=.01, p=.929, \eta_{p}{ }^{2}=.00\right)$, which indicates that the main effect of disclosure design on advertising recognition holds true for both advertising formats. 


\section{Conclusion-Study 3}

The children recognized the child-inspired advertising disclosure better than the existing disclosure designs, though only when exposed to brand placement. In addition, they had a better understanding of the childinspired advertising disclosure and also had a more positive attitude toward it. Finally, the children recognized the commercial content better after exposure to the childinspired disclosure than after exposure to the existing advertising disclosures.

\section{CONCLUSION AND DISCUSSION}

Current advertising disclosures are shown to have deficiencies and seem to be ineffective (An and Kang 2013, 2014; Tessitore and Geuens 2013). We therefore aimed to develop a child-inspired advertising disclosure that can be incorporated into all different media platforms to disclose all different advertising formats to children (ages 6 to 12 years old). Further, we also aimed to examine the effectiveness of the developed advertising disclosure by implementing it into two different advertising formats, namely, online banner advertising and brand placement. This provides some evidence for the applicability of the disclosure in different advertising formats.

Our study confirmed Tessitore and Geuens's (2013) finding that it is necessary to implement an advertising disclosure that stands out with striking colors and shapes. This assertion was clearly supported by the opinions of the children in the cocreation workshops. The children preferred contrasting colors and unconventional shapes. With regard to wording, they clearly preferred reclame, the Dutch word for "advertising."

The first eye-tracking study led to a remarkable finding. Although the children did not pay attention to the advertising disclosures in the upper-right corner, they did notice the online banners. Therefore, this result could not be attributed to the phenomenon of banner blindness, which has often been reported in adults (Drèze and Hussherr 2003; Lee and Ahn 2012). Given that the children looked at the banners centrally, we decided to do a second eye-tracking study in which the advertising disclosures were also placed centrally, on top of the online banners. This change led to a significant difference in attention between the advertising disclosures: The advertising disclosure that attracted the most attention was a rectangular disclosure with a black background and yellow letters (Reclame!). After further refining the disclosure's design, we tested our final advertising disclosure for its effectiveness.

Given that the children from our target group are referred to as "cued processors" in theory, we expected the child-inspired disclosure to assist children in recognizing advertising (John 1999; Roedder 1981). This expectation was confirmed by our study. Although the children were able to recognize the advertising fairly well after exposure to both the existing and the child-inspired advertising disclosures, the child-inspired disclosure led to a higher recognition of commercial content than the existing ones. This suggests that the child-inspired advertising disclosure was able to achieve the activation of the first step of situational advertising literacy: recognizing advertising in order to then activate their associative networks (i.e., their dispositional advertising literacy; Hudders et al. 2017). In addition, the children also better recognized and understood the meaning of the child-inspired disclosure. Further, in line with previous studies (An and Kang 2013; An and Stern 2011; Wojdynski and Evans 2016), our findings suggest that the ineffectiveness of existing advertising disclosures can be attributed to their characteristics and designs. Finally, the strength of this study is that we used children's views and insights as a starting point to develop the advertising disclosure. Results from the experimental study confirm that the children indeed liked the childinspired disclosure more than the existing ones.

Finally, the experimental study showed that the childinspired advertising disclosure can be applicable to multiple advertising formats in different media platforms to successfully disclose advertising to children. In particular, we found that the children's advertising recognition, disclosure understanding, and disclosure preference were higher after exposure to the child-inspired advertising disclosure than after exposure to the currently used disclosures in the contexts of both brand placement and online banner advertising. Our results also indicated that the child-inspired disclosure resulted in higher disclosure recognition than those currently used, but only in the context of brand placement. This may be explained by the fact that a website environment (including online banner advertisements) can be considered a context that is congruent with the child-inspired disclosure, as this is also a text-loaded environment; whereas brand placement, which has an audiovisual nature, can be considered a more incongruent context. The schema-incongruent effect suggests that a new stimulus will be better processed when it goes against expectations (i.e., when it is incongruent with the context; Mandler 1982).

\section{PUBLIC POLICY IMPLICATIONS}

Our research has significant implications for public policy. The results of our studies support the importance of the existing regulations and guidelines, such as the ICC Code and the U.S. FTC's staff guidance document (Federal Trade Commission (FTC) 2013). However, most of these regulations concerning the disclosure of advertising are limited to indicating that advertising should be 
recognizable as such. As a result, digital and embedded advertising formats are often disclosed by many different types of advertising disclosures. In future guidelines and regulations, policymakers should further specify how advertising should be disclosed to children by implementing specific advertising disclosures. We formulate three main recommendations.

First, existing advertising disclosures do not use appropriate language for the target group, even though clear and understandable language for the target group was an important guideline of the FTC's Clear and Conspicuous Standard (Federal Trade Commission (FTC) 2013). Also, synonyms might lead to different associations and, thus, different effects (compare advertising, advertisement, commercial), as these synonyms might not activate children's associative network concerning advertising. To improve children's understanding of advertising disclosures, public policy and regulations should include more specific guidelines for disclosure wording. In particular, policy regulations should focus on using a local translation to provide better results with regard to understandability. In addition, the use of abbreviations as wording for advertising disclosures should be avoided.

Second, the positioning of disclosures on websites to disclose online banner advertising plays a crucial role in their effectiveness. Following the FTC's guidelines, our research suggests that, for children, a central placement is preferred on top of the online banner.

Third, the colors, font, and shape used in the advertising disclosure's design should be prominent and striking. Existing advertising disclosures are often displayed in subtle and neutral colors (such as gray and black), even though striking colors lead to better results in terms of advertising recognition.

Beyond these three recommendations concerning how advertising disclosures for children should look, we deem it extremely important that all stakeholders support the advertising disclosure. Otherwise, this will again result in the development and implementation of various types of advertising disclosures. We believe that the advertising industry, policymakers, and academics should enter into a dialogue to discuss the development of a clear and meaningful advertising disclosure. Regarding the FTC standards, the advertising industry has raised concerns about the FTC being overly prescriptive (Interactive Advertising Bureau (IAB) 2015). Specifically, the Interactive Advertising Bureau (IAB) (2015) emphasized that such guidelines should be technically feasible and should not restrict innovation. Our research clearly established that a child-inspired advertising disclosure could provide better results in disclosure understanding and advertising recognition. However, in contrast to popular belief among advertisers, advertising recognition does not necessarily result in negative advertising effects because this is determined, among other things, by the ad's fairness (De Pauw, Hudders, and Cauberghe 2017). Engaging the advertising industry in the development and implementation of an advertising disclosure will contribute to the feasibility and likelihood of implementing such a disclosure. The implementation of such a disclosure could further result in more transparent and ethical advertising aimed at children.

Especially concerning implementation, many technical issues and questions will arise that must be solved. Most important are whether all media content containing advertising should be required to implement this advertising disclosure (or only media content targeting children) and what exactly is defined as "media content targeting children." Further, should the brand name be mentioned together with the advertising disclosure? This is an especially important question concerning brand placement, as children will now recognize that the media content contains advertising due to the advertising disclosure but may not know which brands are being advertised. In addition, it should be clarified how "advertising" is conceptualized and whether all commercial content is advertising (e.g., company websites, sponsored vloggers). These questions should be further addressed by researchers, policymakers, and the advertising industry.

\section{LIMITATIONS AND FURTHER RESEARCH}

Despite cautious preparations, this study is subject to several limitations that translate into suggestions for future research. First, when evaluating the effectiveness of the child-inspired disclosure, we tested it in the context of only two advertising formats: brand placement and online banner advertising. As our goal was to develop a childinspired advertising disclosure that can be applied to all types of advertising, future studies should examine the usability and effectiveness of the child-inspired disclosure for other digital and embedded advertising formats, such as in-game advertising, advergames, native advertising, and brand placement within vlogs. In addition, future research could examine the underlying mechanisms (e.g., congruence, lean-back versus lean-forward way of watching) that can explain differences in the disclosure's effectiveness between different advertising formats.

The effectiveness of the child-inspired disclosure was also tested among only one age group (10- and 11-yearolds; i.e., one grade within primary school) because the scope of an experimental study needs to be limited. Future research could investigate the impact of the childinspired advertising disclosure (compared to an existing disclosure) among a younger target audience.

Third, the advertising disclosures currently used in Belgium for brand placement and online banner advertising were used in the experimental study. However, the 
disclosures are different for brand placement (a gray, round-shaped disclosure with the PP symbol) and online banner advertising (a black rectangular disclosure with the word Advertenties in white). We used these two different advertising disclosures in our experimental study for the same condition ("existing advertising disclosure") in order to approach reality as closely as possible and because these advertising disclosures cannot be used interchangeably. Given that two different advertising formats and existing advertising disclosures were used, we cannot be sure whether the results are attributed to the different advertising environments, the different existing advertising disclosures, or a combination of both. Future research could examine the effectiveness of the child-inspired advertising disclosure by comparing it with only one other advertising disclosure.

In addition, because advertising recognition is the main goal of advertising disclosures, the current study focused only on the impact of the child-inspired disclosure on children's advertising recognition and disclosure recognition, understanding, and preference. Future research could focus on the impact of the child-inspired advertising disclosure on children's critical processing of the advertisement. This study also did not report the impact of the child-inspired advertising disclosure on advertising effectiveness. Further research could examine the impact of the child-inspired disclosure on advertising effects such as purchase request, brand attitude, attitude toward the ad, word-of-mouth intention, and how advertising recognition (or advertising literacy) mediates the relationship between advertising disclosure and advertising effects in the context of both fair and unfair ads.

Moreover, additional input could be gathered by conducting another qualitative study with the children who participated in the cocreation workshops to check whether the constructed disclosure designs reflected their preferences. The supplementary study could provide insights from the children about their opinions and beliefs about the constructed disclosure designs. This feedback could then be processed, and changes could be made to the disclosure designs accordingly.

Finally, future research is needed concerning the modality, timing, and positioning of the advertising disclosure. Studies could also look at the effectiveness of the child-inspired advertising disclosure in other countries by using a local adaptation of the advertising disclosure.

\section{FUNDING AND ACKNOWLEDGMENTS}

The authors thank Brahim Zarouali, Sofie Strumane, Lara Schollier, Laurens Vantyghem, Inez Vangheluwe, Sofie Janssens, Kaat Geldof, Justine Mathys, and Broud Worme for their help in the collection of the data. This work was supported by the Agentschap Innoveren en Ondernemen (130008) and Research Foundation - Flanders (FWO.3E0.2015.0035.01).

\section{SUPPLEMENTAL DATA}

Supplemental data for this article can be accessed here.

\section{REFERENCES}

An, Soontae, and Susannah Stern (2011), "Mitigating the Effects of Advergames on Children," Journal of Advertising, 40 (1), 43-56.

_, and Hannah Kang (2013), "Do Online Ad Breaks Clearly Tell Kids That Advergames Are Advertisements That Intend to Sell Things?," International Journal of Advertising, 32 (4), 655-78.

, and (2014), "Advertising or Games? Advergames on the Internet Gaming Sites Targeting Children," International Journal of Advertising, 33 (3), 509-32.

- Hyun Seung Jin, and Eun Hae Park (2014), "Children's Advertising Literacy for Advergames: Perception of the Game as Advertising," Journal of Advertising, 43 (1), 63-72.

Bandyopadhyay, Subir, Gurprit Kindra, and Lavinia Sharp (2001), "Is Television Advertising Good for Children? Areas of Concern and Policy Implications," International Journal of Advertising, 20 (1), 89-116.

Bergkvist, Lars, and John R. Rossiter (2007), "The Predictive Validity of Multiple-Item versus Single-Item Measures of the Same Constructs," Journal of Marketing Research, 44 (2), 175-84.

Boerman, Sophie C., Eva A. van Reijmersdal, and Peter C. Neijens (2012), "Sponsorship Disclosure: Effects of Duration on Persuasion Knowledge and Brand Responses," Journal of Communication, 62 (6), 1047-64.

- — Timing on the Processing of Sponsored Content: A Study on the Effectiveness of European Disclosure Regulations," Psychology \& Marketing, 31 (3), 214-24.

, Lotte M. Willemsen, and Eva P. Van Der Aa (2017), “"This Post Is Sponsored': Effects of Sponsorship Disclosure on Persuasion Knowledge and Electronic Word of Mouth in the Context of Facebook," Journal of Interactive Marketing, 38, 82-92.

Boush, David M., Marian Friestad, and Gregory M. Rose (1994), "Adolescent Skepticism toward TV Advertising and Knowledge of Advertiser Tactics," Journal of Consumer Research, 21 (1), 165-75.

Brucks, Merrie, Gary M. Armstrong, and Marvin E. Goldberg (1988), "Children's Use of Cognitive Defenses against Television Advertising: A Cognitive Response Approach," Journal of Consumer Research, 14 (4), 471-82.

Campbell, Margaret C., Gina S. Mohr, and Peeter W.J. Verlegh (2013), "Can Disclosures Lead Consumers to Resist Covert Persuasion? The Important Roles of Disclosure Timing and Type of Response," Journal of Consumer Psychology, 23 (4), 483-95.

De Pauw, Pieter, Liselot Hudders, and Veroline Cauberghe (2017), "Disclosing Brand Placement to Children," International Journal of Advertising, 37 (4), 508-25.

Drèze, Xavier, and Franç,ois-Xavier Hussherr (2003), "Internet Advertising: Is Anybody Watching?," Journal of Interactive Marketing, 17 (4), 8-23.

Federal Trade Commission [FTC] (2013), ".Com Disclosures: How to Make Effective Disclosures in Digital Advertising," March, https:// www.ftc.gov/tips-advice/business-center/guidance/com-disclosureshow-make-effective-disclosures-digital.

Gunter, Barrie, Caroline Oates, and Mark Blades (2004), Advertising to Children on TV: Content, Impact, and Regulation, New York: Routledge.

Hudders, Liselot, Veroline Cauberghe, and Katarina Panic (2016), "How Advertising Literacy Training Affect Children's Responses to Television Commercials versus Advergames," International Journal of Advertising, 35 (6), 909-31. 
- Pieter De Pauw, Veroline Cauberghe, Katarina Panic, Brahim Zarouali, and Esther Rozendaal (2017), "Shedding New Light on How Advertising Literacy Can Affect Children's Processing of Embedded Advertising Formats: A Future Research Agenda," Journal of Advertising, 46 (2), 333-49.

Interactive Advertising Bureau [IAB] (2015), "IAB Concerned about FTC Guidance on Native Advertising," December 24, https://www. iab.com/news/iab-concerned-about-ftc-guidance-on-native-advertising.

International Chamber of Commerce [ICC] (2017), "ICC Code: Article 18 - Children and Young People," http://www.codescentre.com/icccode.aspx\#gen 18.

John, Deborah Roedder (1999), "Consumer Socialization of Children: A Retrospective Look at Twenty-Five Years of Research," Journal of Consumer Research, 26 (3), 183-213.

Kim, Bong-Hyun, Yorgo Pasadeos, and Arnold Barban (2001), "On the Deceptive Effectiveness of Labeled and Unlabeled Advertorial Formats," Mass Communication and Society, 4 (3), 265-81.

Kunkel, Dale, Brian L. Wilcox, Joanne Cantor, Edward Palmer, Susan Linn, and Peter Dowrick (2004), Report of the APA Task Force on Advertising and Children, Washington, DC: American Psychological Association.

Lee, JooWon, and Jae-Hyeon Ahn (2012), "Attention to Banner Ads and Their Effectiveness: An Eye-Tracking Approach," International Journal of Electronic Commerce, 17 (1), 119-37.

Mallinckrodt, Victoria, and Dick Mizerski (2007), "The Effects of Playing an Advergame on Young Children's Perceptions, Preferences, and Requests," Journal of Advertising, 36 (2), 87-100.

Mandler, George (1982), "The Structure of Value: Accounting for Taste," in Affect and Cognition: The 17th Annual Carnegie Symposium, M.S. Clark and S.T. Fiske, eds., Hillsdale, NJ: Erlbaum, 3-36.

Mortelmans, Dimitri (2007), Handboek Kwalitatieve Onderzoeksmethoden [Handbook Qualitative Research Methods], Leuven, Belgium: Acco.

Panic, Katarina, Verolien Cauberghe, and Patrick De Pelsmacker (2013), "Comparing TV Ads and Advegames Targeting Children: The Impact of Persuasion Knowledge on Behavioral Responses," Journal of Advertising, 42 (2/3), 264-73.

Roedder, Deborah L. (1981), "Age Differences in Children's Responses to Television Advertising: An Information-Processing Approach," Journal of Consumer Research, 8 (2), 144-53.

Rozendaal, Esther, Moniek Buijzen, and Patti Valkenburg (2010), "Comparing Children's and Adults' Cognitive Advertising Competences in the Netherlands," Journal of Children and Media, 4 (1), 77-89.

- — , and (2011), "Children's Understanding of Advertisers' Persuasive Tactics," International Journal of Advertising, 30 (2), 329-50.
Laura Buijs, and Eva A. van Reijmersdal (2016), "Strengthening Children's Advertising Defenses: The Effects of Forewarning of Commercial and Manipulative Intent," Frontiers in Psychology, 7, 1186.

Sanders, Elizabeth B.-N., and Pieter Jan Stappers (2008), "Co-Creation and the New Landscapes of Design," Co-Design, 4 (1), 5-18.

Sénéchal, Monique, and Jo-Anne LeFevre (2002), "Parental Involvement in the Development of Children's Reading Skills: A Five-Year Longitudinal Study," Child Development, 73 (2), 445-60.

Tessitore, Tina, and Maggie Geuens (2013), "PP for 'Product Placement' or 'Puzzled Public'? The Effectiveness of Symbols as Warnings of Product Placement and the Moderating Role of Brand Recall," International Journal of Advertising, 32 (3), 419-42.

Valkenburg, Patti M., and Joanne Cantor (2001), "The Development of a Child into a Consumer," Journal of Applied Developmental Psychology, 22 (1), 61-72.

van Reijmersdal, Eva A., Jeroen Jansz, Oscar Peters, and Guda Van Noort (2010), "The Effects of Interactive Brand Placements in Online Games on Children's Cognitive, Affective, and Conative Brand Responses," Computers in Human Behavior, 26 (6), 1787-94.

— Sophie C. Boerman, Moniek Buijzen, and Esther Rozendaal (2017), "This Is Advertising! Effects of Disclosing Television Brand Placement on Adolescents," Journal of Youth and Adolescence, 46 (2), 328-42.

Waiguny, Martin K.J., Michelle R. Nelson, and Ralf Terlutter (2014), "The Relationship of Persuasion Knowledge, Identification of Commercial Intent, and Persuasion Outcomes in Advergames: The Role of Media Context and Presence," Journal of Consumer Policy, 37 (2), 257-77.

Wogalter, Michael S., Amy B. Magurno, Ann W. Carter, Julie A. Swindell, William J. Vigilante, and Jason G. Daurity (1995), "Hazard Associations of Warning Header Components," in Proceedings of the Human Factors and Ergonomics Society Annual Meeting, Los Angeles: Sage, 39, 979-83.

, and Kenneth R. Laughery (1996), "Warning! Sign and Label Effectiveness," Current Directions in Psychological Science, 5 (2), 33-37.

- Vincent C. Conzola, and Tonya L. Smith-Jackson (2002), "Research-Based Guidelines for Warning Design and Evaluation," Applied Ergonomics, 33 (3), 219-30.

Wojdynski, Bartosz W., and Nathaniel J. Evans (2016), "Going Native: Effects of Disclosure Position and Language on the Recognition and Evaluation of Online Native Advertising," Journal of Advertising, 45 (2), 157-68.

Wollslager, M.E. (2009), "Children's Awareness of Online Advertising on Neopets: The Effect of Media Literacy Training on Recall," SIMILE: Studies In Media and Information Literacy Education, 9 (2), $31-53$. 